\title{
Design contribuindo para o envelhecimento ativo: Um estudo sobre o ligamento afetivo a objetos cotidianos vinculados às memórias de histórias de vida em idosos. \\ Design contributing to active ageing: A study on the affective attachment to everyday objects linked to memories of life histories in the elderly.
}

\author{
Angélica P. C. de Souza \& Silvio R. Barreto Campello
}

Teoria da Atividade, idosos, jogo de cartas, Design da Informação, contação de histórias.

\begin{abstract}
Seguindo o princípio do Design que se preocupa não apenas com o "papel do usuário", mas sim com o próprio ser humano - repleto de complexidade e inserido em seu contexto real coletivo - esse artigo apresenta resultados de dissertação de mestrado, por meio de uma análise qualitativa do uso de ferramenta de lazer, projetada para um público complexo e delicado: os idosos. Um jogo de cartas, intitulado "Te contei?", que visa a estimular memórias de vida em uma atividade de compartilhamento de experiências, foi testadocom idosos senescentes, residentes em Pernambuco. As análises foram feitas sob a lente da Teoria da Atividade (T.A.) e neste artigo será relatado o processo de refinamento evolutivo das ferramentas de coleta e análise. Como resultado foi possível compreender de forma aprofundada os efeitos, bem como identificar benefícios e estímulos durante a participação da atividade e a influência de diferentes contextos sociais (laços de relacionamentos positivos, negativos ou neutros) entre os participantes.
\end{abstract}

Activity Theory, elderly, card game, Information Design, storytelling.

Following the principle of the Design that is not only concerned with the "role of the user" but with the actual human being -full of its complexity and involved in a real social context - this article presents the results of a research developed through a qualitative analysis of the use of a leisure tool designed for a complex and delicate audience: the elderly. Tecontei? (Did I tell you?) is a card game that aims to stimulate life memories in an activity of sharing experiences, performed in groups of senescent elderly, residents in Pernambuco. The analyses were done under the lens of the Activity Theory (A.T.) and it is reported in this article the evolutionary refinement process of the tools for data collection and data analysis. As a result, it was possible to understand in depth the effects, as well as to identify benefits and stimuli during the participation of the activity and the influence of the different social contexts (positive, negative or neutral relationship bonds) among the participants.

\section{Introdução}

Na terceira edição do tratado de Geriatria e Gerontologia de 2013, envelhecimento é conceituado como um processo dinâmico e progressivo, no qual há modificações morfológicas, funcionais, bioquímicas e psicológicas que determinam perda da capacidade de adaptação do indivíduo ao meio ambiente, ocasionando maior vulnerabilidade e maior incidência de processos patológicos que terminam por levá-lo à morte (Freitas, Cançado, Doll \& Gorzoni, 2013).

Dentre grandes problemáticas que surgem para esse grupo demográfico altamente diversificado, indo de indivíduos completamente saudáveis e ativos a seriamente frágeis e dependentes, uma realidade é comum: são pessoas que necessitam gradualmente de maior atenção e auxílio de diferentes profissionais.

Ante tamanha fragilidade proveniente do processo de envelhecimento, vê-se que o grupo populacional dos idosos registra, em uma escala mundial, números nunca antes vistos, que se

Anais do 9 CIDI e 9 CONGIC

Luciane Maria Fadel, Carla Spinillo, Anderson

Horta,Cristina Portugal (orgs.)

Sociedade Brasileira de Design da Informação - SBDI

Belo Horizonte | Brasil | 2019

ISBN 978-85-212-1728-2
Proceedings of the 9th CIDI and 9th CONGIC

Luciane Maria Fadel, Carla Spinillo, Anderson Horta, Cristina Portugal (orgs.)

Sociedade Brasileira de Design da Informação - SBDI Belo Horizonte | Brazil | 2019

ISBN 978-85-212-1728-2 
dão graças aos avanços tecnológicos na área medicinal e novas preocupações de cuidado constante com a saúde (incluindo controle alimentar e exercícios físicos regulares).

Com essa possibilidade em vista, a OMS (2005) traz o entendimento que o envelhecimento precisa ser uma experiência positiva. Para expressar essa visão,a organização adotou o termo de "envelhecimento ativo", definido como o processo de otimização das oportunidades de saúde, participação e segurança. O objetivo está em melhorar a qualidade de vida à medida que as pessoas ficam mais velhas, mantendo sua importância e participação ativa nas questões de cidadania, independentemente do seu estado de saúde, capacidades e/ou requerimento de cuidados.

Gruber, Reis e Mazo (2016) compreendem que os idosos passam por situações de constrangimento (tanto de natureza física quanto psicológica) e o motivo muitas vezes está relacionado à falta de atenção e da ineficiência projetual de produtos adequados à esse público, ao deixar de considerar suas limitações e características. Nessa pesquisa, estendemos essa visão incluindo também seus interesses e necessidades.

Souza (2013) apresenta uma pesquisa de similares para jogos de lazer comumente utilizados por idosos. Foi observado que a maioria dos artefatos oferecidos no mercado que intencionam o objetivo de proporcionar atividades estimulantes (principalmente as de estímulo cognitivo) se concentram em dois grupos: (1) jogos baseados em temáticas infantis e (2) jogos de grande complexidade. O primeiro grupo pode desestimular públicos maduros. Enquanto 0 segundo, frustrá-los.

Assim, considerando uma pesquisa para um "Design centrado nos idosos", a problemática tratada inicialmente é tocante à escassez mercadológica de produtos e serviços adequados a esse grupo complexo e em crescimento.

Graças à tamanha diversidade inclusa nesse grupo populacional e à grande fragilidade relativa ao subgrupo que enfrenta as características de senilidade, o recorte dos participantes foi delimitado da seguinte forma: grupos que compreendem idosos senescentes (que apresentam um envelhecimento sadio) e idosos com, no máximo, identificação de DCL (declínio cognitivo leve) por seus familiares.

Durante a pesquisa foi possível testar um jogo de contação de história e estímulo de memória produzido para o público idoso, intitulado "Te contei?". Para tal foram realizados 5 estudos em diferentes contextos que incluíram 21 participantes e um montante de 107 histórias.

Os objetivos incluíram a identificação de ferramentas metodológicas para análise da atividade proposta, descrevendo quais os estímulos identificados, benefícios resultantes e análise da aplicação em diferentes contextos sociais.

Das relações sociais entre os participantes, em dois (2) dos estudososidosos relataram possuir uma relação de amizade, em um (1) foi observado a existência de uma relação de inimizade entre as participantes. Jáo quarto estudo envolveu pessoas com laços familiares (avó e neta) e o último foi aplicadocomidosos que não se conheciam anteriormente, isto é, um ambiente socialmente "neutro".

Em adicional, durante o processo de pesquisa, o artefato em si pôde ser adaptado de acordo com as percepções e análises construídas. Como resultado, foi possível desenvolver dois designs para as cartas com diferentes potenciais interpretativos e emocionais, um baseado em fotografias e outro baseado em símbolos.

\section{Design da informação e idosos}

Em suma, os projetos desenvolvidos para pessoas idosas devem procurar compensar e eliminar (ou minimizar) as dificuldades recorrentes. Tanto na usabilidade quanto na compreensão das mensagens a serem transmitidas, o objetivo está no processo de facilitar o alcance dos objetivos.

Shedroff (1999) fala que o desenvolvimento de produtos informacionais é um processo 
complexo e para possuir valor informacional, os dados precisam ser organizados, transformados e apresentados de uma forma que provenha significado.

É a partir dessa compreensão que, de uma forma visual, clara e ainda assim ampla para interpretação, foi escolhido por Souza em 2013, durante a criação do jogo "Te contei?", o uso de imagens que tornasse possível o estímulo da memória. A partir dessa necessidade e do desejo de utilizar o fator emocional como catalisadores do processo de recordação, foi escolhido para o jogo a inclusão de imagens representativas de um grupo de artefatos que comumente são carregados de significados pessoais.

Esses artefatos possuem a capacidade de transportar o seu dono para um momento específico em sua vida, pois estão conectados a pessoas ou acontecimentos especiais marcantes. Tal descoberta está diretamente conectada com os trabalhos da professora doutora Vera Damazio, forte interlocutora e pesquisadora dos chamados "Artefatos de Memória" (Damazio, 2005, 2006).

\section{0 jogo}

Souza (2013) desenvolveu uma forma de potencializar as chances de estímulo de memória estudando os elementos que constituem o processo narrativo. Para isso, a autora Cândida Gancho diz que toda narrativa se estrutura sobre cinco elementos, sem os quais ela não existe.

'Sem os fatos não há história, e quem vive os fatos são os personagens, num determinado tempo e lugar. Mas para ser prosa de ficção é necessária a presença do narrador, pois é ele fundamentalmente que caracteriza a narrativa' (Gancho, 2002, p. 9).

Das cinco categorias de Gancho, três foram diretamente aplicadas na atividade com objetivo de prover mais informações indicativas para auxílio do processo de recordar memórias de vida. Dessa forma, o baralho desenvolvido foi segmentado em 3 principais categorias: personagem, cenário e acontecimento. A figura 1 demonstra as cartas e as placas de pontuação.

Figura 1: Cartas nas três categorias e placas para pontuação. Fonte: SOUZA (2013)
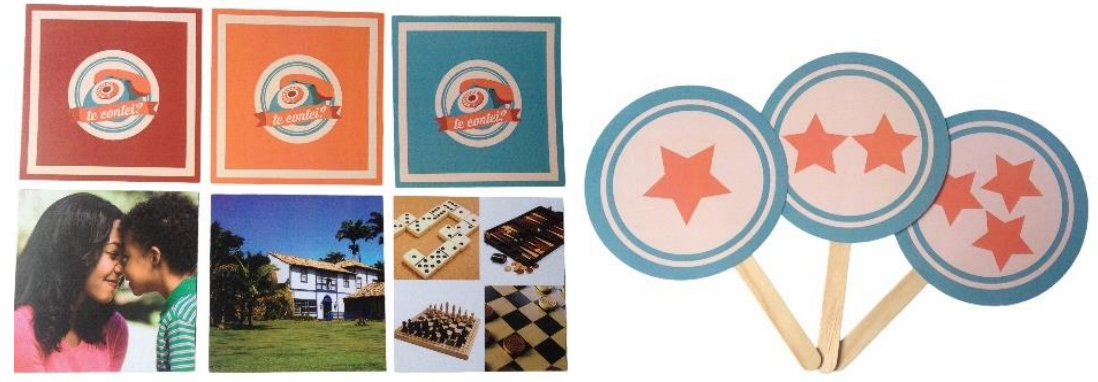

\section{Como jogar}

Cada jogador, em sua vez, deve sortear aleatoriamente 3 cartas, uma de cada categoria e assim devem contar uma (1) história (verídica ou não) na interpretação de ao menos uma das cartas sorteadas.

Ao final da contação de cada história, os demais jogadores utilizando as placas de julgamento, apresentarão uma pontuação que deve ser somada para se alcançar o objetivo do jogo. Um jogador deve ficar responsável por anotar as pontuações para que, ao final de 4 rodadas, aquele que possuir o maior placar adquirido pela soma das estrelas, vence.

- Regra "Se aproveitando": Essa regra pode ser utilizada entre os jogadores que estejam no momento de julgar. Caso haja participantes que tenham uma história que se encaixe nas cartas escolhidas por outro jogador, estes poderão igualmente "se aproveitar" da oportunidade e também compartilhar histórias com intuito de aumentar seu placar em exatamente um ponto. 
- Regra "Salve uma carta": Um jogador, ainda que não esteja na sua rodada (isto é, jogador responsável por julgar), pode "salvar" uma carta escolhida por outro jogador (pegar e segurá-la) para utilizar na sua vez, após o participante da rodada finalizar a sua história.

\section{Teoria da Atividade (T.A.)}

Barreto Campello $(2005,2009)$ apresenta a Teoria da Atividade como um modelo sociocultural que concebe toda ação humana como mediada por artefatos (sejam eles materiais e/ou psicológicos) e orientada à obtenção de determinados objetivos. A T.A. expandiu o conceito de Ação Mediada de Vigotski (Werstch, 1991), desenvolvendo a noção de que ela se realiza dentro de uma atividade social (Leontiev 1979). Dessa forma, concebeu uma tríade hierárquica - Atividade-Ação-Operação - que inter-relaciona estados mentais com os níveis social, individual e motor.

Leontiev parte do pressuposto que a atividade humana é formada por ações coletivas e individuais e que estas são formadas pelo que chamou de operações. O primeiro nível está diretamente relacionado ao motivo pelo qual se realiza a atividade, o segundo, relacionado a metas específicas que conduzem à consecução do primeiro, e o terceiro que é definido pelas circunstâncias e se dá de forma menos consciente (tabela 1).

Tabela 1: - Níveis hierárquicos do sistema da prática-social segundo modelo de LeontievFonte: BARRETO CAMPELLO (2009)

\begin{tabular}{|l|l|l|}
\hline Nível & Fator de orientação & Natureza \\
\hline Atividade & Motivo & Coletiva e consciente \\
\hline Ação & Meta & Individual e consciente \\
\hline Operação & Circunstância & Individual e inconsciente \\
\hline
\end{tabular}

A elaboração feita por Leontiev foi representada por Engeström em 1987 no diagrama a seguir (figura 2), no qual os elementos "sujeito", "artefato" e "objetivo" são compreendidos em um sistema macro e complexo. O diagrama de Engeström enfatiza em sua metade superior o conceito de Ação Mediada e na inferior os aspectos sociais do sistema proposto por Leontiev, elicitando o corpo social em que a ação ocorre, a divisão de trabalho e as regras que estruturam a atividade.

Figura 2: Modelo do sistema evoluído da T.A. Fonte: Engeström (1987) a partir dos trabalhos de Leontiev.

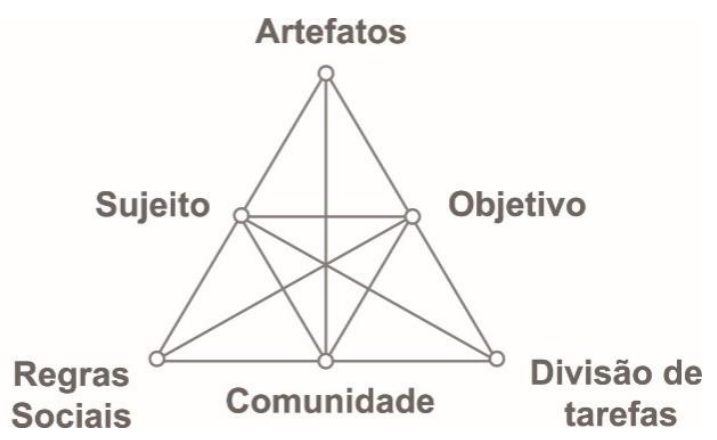

É importante salientar que um sistema de atividade não é constante e sim dinâmico, variável e suscetível a evoluções. Essa noção é introduzida ainda por Engeström (1999) como contradições, se referindo aos problemas e conflitos que ocorrem no sistema. 
Com base no conceito decontradições, Mwanza (2000) propõe uma decomposição em tríade dos componentes do modelo expandido deEngeström para realizar análises mais aprofundadas (tabela 2), focando nas duas principais relações do sistema (o sujeito e a comunidade), tencionando sempre ao objeto, incluindo como mediadores os demais elementos (ferramentas, as regras sociais e a divisão do trabalho).

Tabela 2: - Estrutura de notação. Fonte: MWANZA (2000)

\begin{tabular}{|c|c|c|c|}
\hline SUJEITO & FERRAMENTA & - & OBJETO \\
\hline SUJEITO & REGRAS SOCIAIS & - & OBJETO \\
\hline SUJEITO & DIVISÃO DE TRABALHO & & OBJETO \\
\hline COMUNIDAD & - FERRAMENTA & - & OBJETO \\
\hline COMUNIDADI & - REGRAS SOCIAIS & - & OBJETO \\
\hline COMUNIDADI & DE - DIVISÃO DE TRABAL & $\mathrm{HO}$ & OBJETO \\
\hline
\end{tabular}

Fundamentado nessas três principais formulações da T.A., foi possível desenvolver os instrumentos de coleta. As categorias da metodologia foram extrapoladas, elaborando novas categorias de análise (mais específicas e assertivas) relativas aos participantes, à atividade e ao artefato em si.

Já as análises foram embasadas nas duas principais estruturas analíticas metodológicas: o modelo do sistema de Engeström e os níveis hierárquicos de Leontiev.

Nessa pesquisa, foi observado dois tipos de contexto: ambientes privados (inseridos na moradia de participantes) e ambientes institucionais (instituições com programas que oferecem atividades de benefícios diversos para idosos). Para o contexto institucional foi escolhido o programa "Vida Ativa", fornecido pelo governo do estado de Pernambuco pela Fundação de Aposentadorias e Pensões dos Servidores (FUNAPE).

A fase experimental se deu pela aplicação da atividade de lazer e constituiu um processo evolutivo de testes. A cada estudo aplicado com os idosos, as observações e análises resultaram em uma evolução na metodologia de coleta, geraram insights provindos da recorrência dos dados e aprimoramento da ferramenta.

\section{Processo evolutivo dos estudos aplicados}

\section{Protocolo inicial e primeira ficha}

O primeiro estudo teve uma característica de "teste aberto", isto é, não estruturado, desprovido de protocolos, instrumentos de coleta ou análise de dados. A partir desse primeiro teste foi possível:

1. Identificar ações importantes a serem inseridas em um protocolo da aplicação da atividade (como as gravações em vídeo e as informações essenciais a serem explicadas para os participantes antes do jogo);

2. Criar o primeiro fichamento (FICHA 1) que entrou no processo para ser preenchido logo após a finalização da atividade. Os pontos incluídos foram observados durante a atividade e serviram para a criação de 11 categorias com campos abertos para anotações pontuais (tabela 3 ). 
Tabela 3: FICHA 1- Análise pós atividade. Fonte: SOUZA (2019)

\begin{tabular}{|l|l|}
\hline CATEGORIAS & OBSERVAÇÕES \\
\hline Benefício para a memória & \\
\hline Benefício social & \\
\hline Benefício físico & \\
\hline Jogabilidade & \\
\hline Dinâmica & \\
\hline Engajamento & \\
\hline Agradabilidade & \\
\hline Dificuldades físicas & \\
\hline Dificuldades Cognitivas & \\
\hline $\begin{array}{l}\text { Estímulo visual para } \\
\text { contação de histórias }\end{array}$ & \\
\hline $\begin{array}{l}\text { Estímulo interpessoal para } \\
\text { contação de histórias }\end{array}$ & \\
\hline
\end{tabular}

\section{Entrevista semiestruturada e segunda ficha}

Após o segundo estudo (que apresentou maior controle da aplicação), o processo de coleta de dados pôde ser incrementado. Foi possível:

1. Criar duas entrevistas semiestruturadas e desenvolvidas com base na decomposição em tríades de Mwanza. Projetadas para serem feitas com os idosos e com o profissional especialista responsável pelo grupo (se presente);

O foco para as triangulações são relacionados aos sujeitos (idosos), à comunidade (de acordo com os diferentes contextos) e a ferramenta (jogo "Te contei?"). Esses três pontos relacionados sempre ao objetivo da atividade. Segue exemplos na tabela 4.

Tabela 4: - Exemplificação das perguntas criadas com base em Mwanza (2000)

\begin{tabular}{|l|l|}
\hline Tríade & Pergunta criada \\
\hline SUJEITO - FERRAMENTA - OBJETIVO & $\begin{array}{l}\text { Alguma coisa nessa atividade foi difícil? } \\
\text { O que foi bom e o que foi ruim? }\end{array}$ \\
\hline SUJEITO - REGRAS - OBJETIVO & As regras são difíceis de entender? \\
\hline SUJEITO - DIVISÃO DE TRABALHO - OBJETIVO & $\begin{array}{l}\text { Qual a melhor parte do jogo? Contar ou ouvir } \\
\text { histórias? Por que? }\end{array}$ \\
\hline
\end{tabular}

2. Criar o segundo fichamento para ser utilizado como coleta de dados durante a atividade (FICHA 2), tornando o processo mais eficiente (figura 3).

Focado em tópicos identificados como importantes para a atividade e que foram vistos constantemente nos dois primeiros estudos, tal ferramenta possibilitou uma análise mais objetiva e que foi estruturada para ser preenchida a cada nova rodada de cada participante.

Dois campos principais foram definidos: o que se refere à atividade e o que se refere aos 
estímulos já identificados. No campo da atividade foi possível observar a relação de interpretação conjunta ou separada das cartas sorteadas (isto é, se os idosos conseguiam correlacionar ao menos duas das cartas selecionadas em apenas uma história), e sobre as possíveis dificuldades identificadas na dinâmica do jogo.

No campo dos estímulos, foi possível perceber três grandes áreas que poderiam ser influenciadas pela atividade: o estímulo da memória (no processo de relembrar experiências vividas), o estímulo social (referente a atenção e a influência das histórias compartilhadas como novos gatilhos de recordação) e o estímulo motor (referente ao ato de gesticular durante contação de história).

Figura 3: FICHA 2- Análise durante a atividade. Fonte: SOUZA (2019)

\begin{tabular}{|l|l|}
\hline Quantidade de participantes: & Obs: \\
\hline Contexto: & \\
\hline Idades: & \\
\hline Partidas/tempo de duraçăo da atividade: & \\
\hline
\end{tabular}
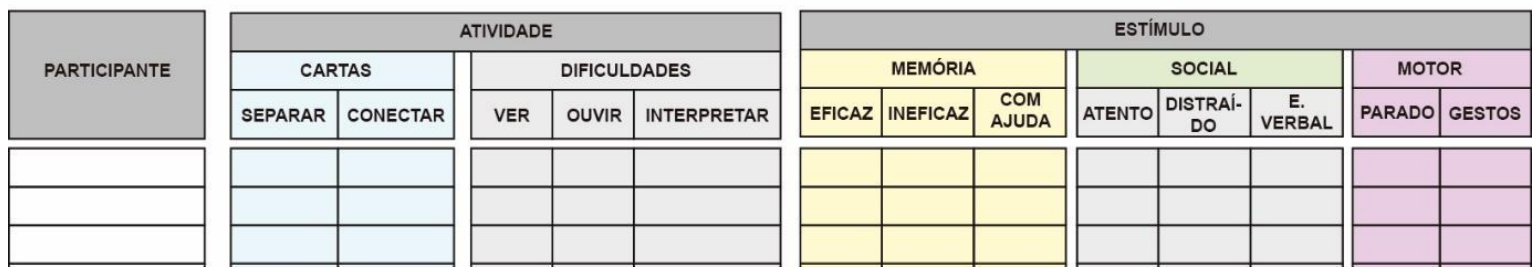

Assim, a partir dos dois primeiros estudosfoi possível passar por uma evolução e adequação no processo de coleta e análise da atividade. Iniciado por simples observação, o processo foi concretizado com protocolos, gravações de vídeo, transcrições, ferramentas de coleta e planilhas de análise.

Ao final dos cinco estudos aplicados, todos os dados coletados foram analisados utilizando o software MAXqda. Essa ferramenta foi escolhida por ser adequada para análise de dados qualitativos e métodos mistos, auxiliando no processo de organização, análise, visualização e publicação de dados.

\section{Alterações no artefato (regras, baralho fotográfico e baralho simbólico)}

Outro acontecimento dentro do processo de pesquisa foram as alterações no próprio artefato, que se tornaram possíveis graças aos estudos e análises da experimentação da atividade.

As primeiras adaptações ocorridas na ferramenta foram relacionadas às regras:

1. Eliminação da fase de julgamento devido a um momento de atrito entre duas participantes que possuíam uma relação de inimizade. Situação ocorreu graças ao desagrado de uma das idosas por não ter recebido a pontuação máxima sobre uma de suas memórias compartilhadas. A hipótese levantada é que a atribuição do julgamento de uma história pessoal junto à uma pontuação provoca um ambiente "competitivo" e, dependendo da relação entre os participantes, pode se aproximar do hostil.

2. Eliminação da regra "salve uma carta" devido ao simples desuso, demonstrando assim o pouco "valor" que a regra agregava à dinâmica do jogo.

A segunda adaptação à ferramenta foi relacionada à mudança do estiloda representação gráfica nascartas. Na primeira versão do jogo, asimagens foram baseadas em fotografias, muitas das quais, exibindo imagens em um estilo "vintage" (principalmente dos artefatos de memória) (figura 4). A escolha das fotografias se deu pela proximidade com a realidade e 0 potencial emotivo que poderia ser intensificado, objetivando a melhor forma de promover 0 estímulo da memória. 
Figura 4: Cartas Acontecimento- TELEVISÃO e VITROLA- fotografia. Fonte: SOUZA (2019)
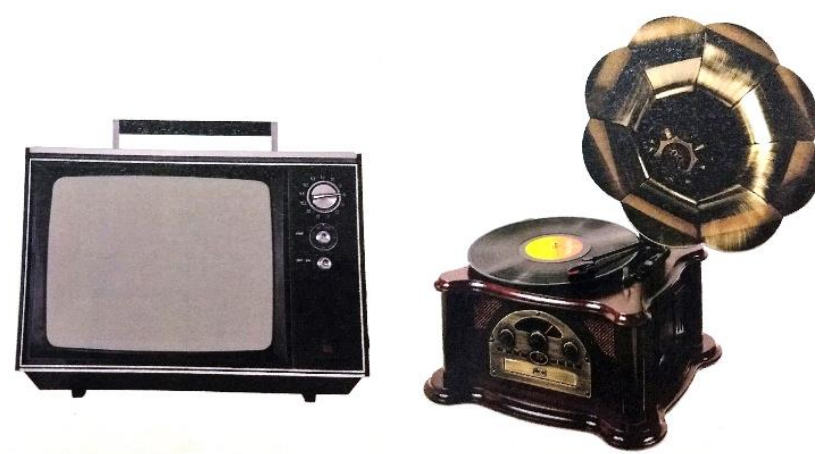

Porém, durante os três primeiros estudos, foi possível perceber que ocorria de modo constante uma interferência no processo de interpretação graças ao uso das fotografias nas cartas: o condicionamento da imagem. Por diversas vezes foi observado que o idoso poderia ser induzido a contar uma história que expressasse uma ou mais características exibidas nas fotografias.

Um exemplo que torna claro esse acontecimento pode ser demonstrado pela carta temática "homem sozinho" (figura 5).

Figura 5: Carta personagem- HOMEM SOZINHO- fotografia. Fonte: SOUZA (2019)

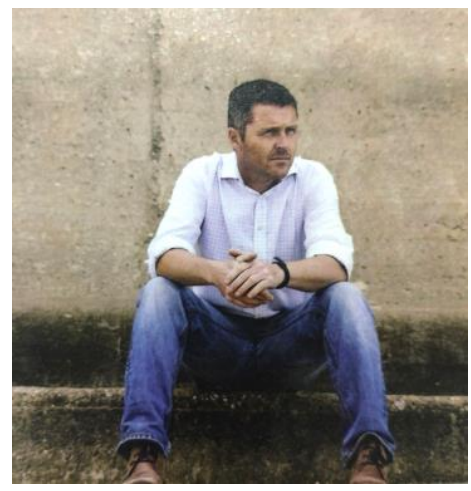

Nesta carta, uma das idosas de etnia indígena viu na imagem de um homem caucasiano o seu relativo mais próximo que possuísse a mesma característica. Nesse caso, a história compartilhada girou em torno de seu tio, homem italiano e único parente de pele mais clara. Ademais, a própriasugestão da faixa etária do personagem se deu como outra característica que também influenciou no processo interpretativo, cuja imagem foi constantemente atribuída a homens "mais velhos", sendo assim interpretada como"pai" ou "tio".

Esse tipo de influência direta foi o que impulsionou a modificação das representações gráficas. A alteração foi feita de fotografias para símbolos, no intuito de eliminar um possível condicionamento da imagem e possibilitar mais liberdade interpretativa aos participantes.

Como exemplo, a carta com a mesma temática "homem sozinho" no baralho de símbolos (figura 6) pôde por sua vez ser interpretada de um modo diferente. Não mais presa ao condicionante da representação da idade, uma participante pôde interpretá-la como uma criança, seu bisneto de apenas 5 anos de idade. 


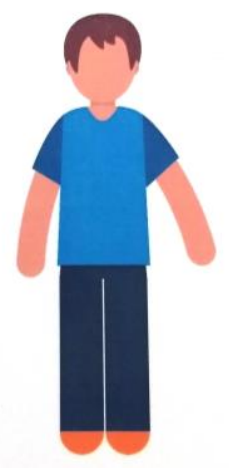

Devido a característica evolutiva do processo de experimentação da ferramenta e análise da atividade, a tabela 5 apresenta as características de cada estudo:

Tabela 5: - Sumário das características dos estudos aplicados com os idosos. Fonte: elaborada pelos autores (2019)

\begin{tabular}{|c|c|c|c|c|c|}
\hline Estudo & $1^{\circ}$ & $2^{\circ}$ & 30 & $4^{\circ}$ & $5^{\circ}$ \\
\hline Contexto & $\begin{array}{l}\text { Grupo } \\
\text { religioso }\end{array}$ & $\begin{array}{l}\text { Grupo } \\
\text { religioso }\end{array}$ & $\begin{array}{l}\text { Institucional } \\
\text { Vida Ativa } \\
\text { (FUNAPE) }\end{array}$ & Privado & $\begin{array}{l}\text { Institucional } \\
\text { Vida Ativa } \\
\text { (FUNAPE) }\end{array}$ \\
\hline $\begin{array}{l}\text { Relacionamento } \\
\text { entre } \\
\text { participantes }\end{array}$ & Amizade & Inimizade & Amizade & $\begin{array}{l}\text { Família } \\
\text { (Avó e neta) }\end{array}$ & $\begin{array}{l}\text { "Neutro" } \\
\text { (desconhecidos } \\
\text { entre si) }\end{array}$ \\
\hline Tipo de baralho & Fotográfico & Fotográfico & Fotográfico & Símbolos & Símbolos \\
\hline $\begin{array}{l}\text { Instrumento de } \\
\text { coleta }\end{array}$ & $x$ & $\begin{array}{l}\text { Gravações e } \\
\text { ficha } 1\end{array}$ & $\begin{array}{l}\text { Gravações, } \\
\text { entrevista, } \\
\text { ficha } 1 \mathrm{e} \\
\text { ficha } 2\end{array}$ & $\begin{array}{l}\text { Gravações, } \\
\text { entrevista, } \\
\text { ficha } 1 \mathrm{e} \\
\text { ficha } 2\end{array}$ & $\begin{array}{l}\text { Gravações, } \\
\text { entrevista, } \\
\text { ficha } 1 \text { e } \\
\text { ficha } 2\end{array}$ \\
\hline
\end{tabular}

\section{Resultados}

Dentre vários resultados que foram alcançados na pesquisa, três serão apresentados nesse artigo:

\section{Benefícios identificados}

O benefício da memória junto ao uso da ferramenta como gatilho para a recordação ofereceu o exercício no âmbito cognitivo, porém não foi o único benefício identificado. Na observação da aplicação da atividade inserida em contextos reais, regidos por laços sociais e sentimentos, foi perceptível dois outros fortes benefícios: social e motor.

O idoso é colocado como centro das atenções na atividade, compartilhando suas experiências e se vendo valorizado, abrindo portas para aproximar familiares ou fazer novas amizades. Esse tipo de benefício reposiciona o idoso, antes desvalorizado e muitas vezes sozinho, para se ver ativo em uma experiência grupal.

Já sobre o campo de estímulo motor, foi observado que naturalmente o corpo foi constantemente usufruído pelos idosos como uma ferramenta complementar no processo de contação de histórias. Assim, de modo confortável, tal acontecimento retira-os de um estado estacionário e estimula movimentações de braços, mãos e até o corpo todo. 


\section{Estímulos para contação de histórias}

- Estímulo visual: Trata-se do uso da imagem exposta na carta como estímulo independente e suficiente para impelir o processo de recordação.

- Estímulo interpessoal: Mediante a atividade grupal repleto de contatos sociais para diferentes contextos, o estímulo interpessoal foi identificado como formas dos demais participantes oferecerem, oralmente, outros gatilhos eficazes para o processo de recordação. Esse estímulo pode ser identificado em três momentos: identificação com experiências semelhantes, complementação e questionamentos.

- Estímulo intrapessoal: Este estímulo é caracterizado pelo desencadeamento de memórias. O idoso segue uma conexão de significados no processo de interpretação, alcançando um tema que, apesar de não ser explícito na carta,alcança um resultado tangente, mas ainda assim, lógico (exemplo: carta CASAL- sinapses: amorcasamento- filhos- netos, resultante: história sobre os netos).

\section{Influência dos laços sociais entre participantes}

Durante a atividade, foi observado que a participação ativa dos participantes, a proatividade na intervenção auxiliar e a atmosfera favorável e prazerosa variavam de acordo com os diferentes contextos observados. Os cenários resultantes da atividade aconteceram de forma dependente e correlacionada com os diferentes contextos de aplicaçãoe os relacionamentos entre os indivíduos.

Nos estudos em que os idosos se consideravam amigos, a atividade seguiu em uma dinâmica leve, fluida e agradável. O interesse nas histórias contadas, a atenção e participação ativa de todos os envolvidos se mantiveram positivos durante toda a partida, caracterizando assim um cenário fértil e promissor.

Porém, um cenário negativo também foi observado, onde as participantes possuíam relacionamentos conturbados entre si, afetando diretamente na dinâmica da atividade. $O$ desinteresse em escutar as histórias compartilhadas e até mesmo momentos de conflito graças à fase de julgamento, levaram à finalização da aplicação do jogo. Como resultado, apesar da atividade ter tido êxito no campo do estímulo das memórias, a dinâmica foi prejudicada.

Já o quinto estudo, aplicado em um ambiente "neutro", teve potencial para se tornar qualquer um dos dois cenários anteriores (positivo ou negativo). Temáticas que incentivam empatia teve potencial para aproximar os participantes, porém, temáticas delicadas que possuem grande potencial para segmentação, ao elucidadas, causaram desconforto e problemas durante a atividade.

\section{Conclusões}

A experiência observada do "Te contei?"proporcionou momentos produtivos em diferentes âmbitos (físico, cognitivo, social e afetivo). Na aplicação do jogo foi oportunizado o posicionamento do idoso sob um holofote de atenção, experimentando uma ferramenta que tornou possível a experiência de partilhar, em uma atividade social, os conhecimentos de uma vida completa de experiências.

Parte dos potenciais identificados incluíram o compartilhamento de alegrias, vitórias, primeiras vezes, acentuação de curiosidades e identificação de experiências em comum. À nível afetivo, foi observado sentimentos aflorados, com situações engraçadas que acarretaram em risadas ou comoventes que resultaram em lágrimas.

Esse artigo objetivou reportar dois frutos recorrentes da pesquisa produzida focada na análise da atividade de lazer para idosos: o processo evolutivo do próprio caminho percorrido durante a fase experimental do projeto e três dos resultados gerados pelas análises produzidas sob a ótica da T.A.

Apesar da aplicação direta dos conhecimentos da metodologia principal, foi a extrapolação 
de suas categorias que propiciou o desenvolvimento de ferramentas adequadas, personalizadas e específicas, garantindo um formato adequado e que tornou o próprio processo de pesquisa mais assertivo e eficiente. Essas ferramentas desenvolvidas podem ainda ser melhoradas e replicadas em contextos similares.

Graças ao diagrama de Engeström e sua visão coletiva do sistema da atividade foi possível observar dois importantes acontecimentos: os benefícios gerados pela atividade e a influência das relações sociais entre os participantes. Em sua concepção o artefato consistia em um estímulo visual que resulta em uma história de vida narrada pelo participante, porém a aplicabilidade e análises demonstraram que entre os benefícios identificados houve a superação das expectativas. Inicialmente concentradas no benefício para a memória, ao final, houve a extensão de ganhos no âmbito social e motor, campos esses que igualmente sofrem declínios durante a fase mais avançada da vida.

Já a observação individual de Leontiev e a tríade dos níveis hierárquicos da prática-social possibilitou a compreensão dos diferentes estímulos que ocorriam à nível operacional do processo de interpretação. O montante dos três gatilhos viabilizou a recordação das memórias de maneira natural e descomplicada.

O estímulo visual veio acompanhado do estímulo intrapessoal (do próprio desencadeamento de memórias) e do estímulo interpessoal (da influência das histórias compartilhadas em grupo), garantindo assim resultados quantitativamente relevantes referentes às memóriascompartilhadas durante a atividade. Consequentemente, garantindo também o alto índice de sucesso e o reforço positivo para os participantes.

Para pesquisas futuras, considerando que foi realizado apenas um estudo no contexto familiar, novas experimentações dentro desse modelo ainda podem gerar diferentes resultados, passíveis de maiores aprofundamentos. Além disso, para mais conclusões sobre o jogo "Te contei?", sugere-se a inclusão de cartas personalizadas com fotografias pessoais, usufruindo do condicionamento da imagem de modo planejado.

\section{Referências}

Barreto Campello, S. R. (2005). Usability for Learning: A Socio-Cultural Approach to usability of VLEs. (Doctoral dissertation, University of Reading). Retrieved from https://www.researchgate.net/publication/312303353_Usability_for_Learning_A_SocioCultural_Approach_to_Usability_of_VLEs

Barreto Campello, S. R. (2009). Aprendizagem Mediada por Computador. Selected Readings on Information Design: Communication, Technology, History and Education. Retrieved from https://www.academia.edu/3568619/Aprendizagem_Mediada_por_Computador

Csikszentmihalyi, M., \&Rochberg-Halton, E. (1981). The Meaning of Things: Domestic Symbols and the Self. In ContemporarySociology (Vol. 12). https://doi.org/10.2307/2067526

Damazio, V. (2005). Artefatos de memória da vida cotidiana: um olhar sobre as coisas que fazem bem lembrar (Tese de Doutorado. Programa de Pós-Graduação em Ciências Sociais, Universidade do Estado do Rio de Janeiro, Rio de Janeiro).

Damazio, V. (2006). Design e Emoção: alguns pensamentos sobre artefatos de memória. P\&D Design.

Engeström, Y. (1987). Learning by Expanding: An Activity- Theoretical Approach to Developmental Research. Helsinki: Orienta-Konsultit Oy, 368. https://doi.org/10.1016/j.intcom.2007.07.003

Engeström, Y. (1999). Innovative learning in work teams: Analyzing cycles of knowledge creation in practice. Perspectives on Activity Theory, 377-404. https://doi.org/10.1017/CBO9780511812774.025

Freitas, E. V., Cançado, F. A. X., Doll, J., \& Gorzoni, M. L. (2013). Tratado de Geriatria e Gerontologia. In E. V. Freitas \& L. Py (Eds.), Journal of Chemical Information and 
Modeling (3a edição, Vol. 53). https://doi.org/10.1017/CBO9781107415324.004

Gancho, C. V. (2002). Como Analisar Narrativas (Série Prin). São Paulo: Editora Ática.

Gruber, C., Reis, A. A. dos, \&Mazo, G. Z. (2016). Ergonomia e envelhecimento : um estudo sobre o desconforto no uso do sutiã por mulheres idosas. 180 Congresso Brasileiro de Ergonomia, (May). Belo Horizonte- MG.

Kuutti, K. (1996). Activity theory as a potential framework for human- computer interaction research. Context and Consciousness: Activity Theory and Human Computer Interaction, 17-44. https://doi.org/citeulike-article-id:634717

Mwanza, D. (2000). Mind the Gap : Activity Theory and Design. CSCW 2000 Conference, (April).

Organização Mundial da Saúde. (2005). Envelhecimento ativo: uma política de saúde (1a edição). https://doi.org/10.1016/S0140-6736(12)61031-9

Rabelo, D. F. (2009). Declínio cognitivo leve em idosos: fatores associados, avaliação e intervenção. Revista Mineira de Ciências Da Saúde, (1), 56-68.

Shedroff, N. (1999). Information Interaction Design: A unified field theory of Design. In R. Jacobson (Ed.), Information Design (pp. 267-292). Cambridge, Massachusetts: The MIT Press.

Souza, A. P. C. de. (2013). Artefatos de memória auxiliando no tratamento de estímulo cognitivo para idosos (Projeto de conclusão. Bacharelado em Design, Universidade Federal de Pernambuco, Pernambuco).

Vigotski, L. S. (1978). Mind in Society: The Development of Higher Psychological Processes. Harvard university press. https://doi.org/10.1007/978-3-540-92784-6

Wertsch, J. V. (1991) Voices of the mind: A sociocultural approach to mediated action. Cambridge, USA: Harvard University Press. pp 6-17.

\section{Sobre os autores}

Angélica Porto Cavalcanti de Souza, Msc., UFPE, Brasil <aportocs@gmail.com>

Silvio Romero Barreto Campello, PhD, UFPE, Brasil < sbcampello@gmail.com> 